\title{
ORIGINAL ARTICLE Irf4 is a positional and functional candidate gene for the control of serum IgM levels in the mouse
}

\author{
J Côrte-Real, J Rodo, P Almeida, A Coutinho, J Demengeot and C Penha-Gonçalves \\ Instituto Gulbenkian de Ciência, Oeiras, Portugal
}

\begin{abstract}
Natural IgM are involved in numerous immunological functions but the genetic factors that control the homeostasis of its secretion and upholding remain unknown. Prompted by the finding that C57BL/6 mice had significantly lower serum levels of IgM when compared with $B A L B / C$ mice, we performed a genome-wide screen and found that the level of serum IgM was controlled by a QTL on chromosome 13 reaching the highest level of association at marker D13Mit266 (LOD score =3.54). This locus was named IgMSC1 and covered a region encompassing the interferon-regulatory factor 4 gene (Irf4). The number of splenic mature B cells in C57BL/6 did not differ from BALB/c mice but we found that low serum levels of IgM in C57BL/6 mice correlated with lower frequency of lgM-secreting cells in the spleen and in the peritoneal cavity. These results suggested that C57BL/6 mice have lower efficiency in late B-cell maturation, a process that is highly impaired in Irf4 knockout mice. In fact, we also found reduced IIf4 gene expression in B cells of C57BL/6 mice. Thus, we propose Irf4 as a candidate for the IgMSC1 locus, which controls IgM homeostatic levels at the level of B-cell terminal differentiation.
\end{abstract}

Genes and Immunity (2008) 0, 000-000. doi:10.1038/gene.2008.73

Keywords: serum IgM; homeostasis; IRF4

\section{Introduction}

Natural IgM play a significant role in the immunology of health and disease. IgM antibodies are involved in numerous immunological functions including protection against infection, ${ }^{1-3}$ prevention of autoimmunity, ${ }^{4,5}$ B-cell homeostasis $^{6-8}$ and immunosurveillance against tumors. ${ }^{9,10}$ IgM biological roles also include opsonization of apoptotic cells, resulting in accelerated clearance by phagocytic cells. ${ }^{11}$ Many of the circulating IgM correspond to natural antibodies that exist prior to infection or immunization. ${ }^{12-14}$ Natural IgM are polyreactive to evolutionary conserved structures ${ }^{15}$ and bind efficiently to previously un-encountered antigen. ${ }^{16}$ These antibodies compensate their low-antigen affinity with relatively high avidity and furthermore the effectiveness of the antigen-antibody interaction is enhanced by the high efficiency of IgM in engaging the complement pathway. ${ }^{11,17}$

The preimmune $\mathrm{Ig}$ repertoire is thought to be composed by mature B cells either recirculating through follicles of secondary lymphoid organs (B2 cells), or joining compartments in specific locations as the marginal zone in the spleen (MZ B-cells) and the pleural or peritoneal cavities (B1 cells). ${ }^{12}$ B2 and marginal zone $\mathrm{B}$-cell development is initiated in the bone marrow and completed in the periphery ${ }^{18,19}$ throughout life. B cells

Correspondence: Dr C Penha-Gonçalves, Instituto Gulbenkian de Ciência, Apartado 14, Oeiras P-2781-901, Portugal.

E-mail: cpenha@igc.gulbenkian.pt

Received 18 July 2008; revised 13 August 2008; accepted 27 August 2008 exported from the bone marrow maturate in the spleen ${ }^{20}$ into subsets that differ in their surface phenotype, anatomic localization and immunologic function ${ }^{21-23}$ and that ultimately are able to differentiate into antibody-producing plasma cells, upon antigenic stimulation. ${ }^{18}$ Most frequently primary antigen contact of mature naive $B$ cells leads to IgM production detectable in the serum.

On the other hand, studies on germ-free and axenic mice suggest that in the absence of pathogens such stimulation is conveyed by the action of self-antigens, leading to production of natural antibodies. ${ }^{24,25}$ The B1 cell population, is derived almost exclusively from foetal liver, ${ }^{26}$ is established early in ontogeny and is predominantly maintained by self-replenishment. ${ }^{27}$ These cells locate preferentially in the pleural and peritoneal cavities $^{26}$ and spontaneously secrete natural Ig $^{28}$ participating in relatively few antigen-stimulated antibody responses. ${ }^{26}$

The capacity for Ig secretion is acquired in the process of B-cell terminal differentiation, ${ }^{29}$ at the plasma cell stage and requires the expression of the transcription factor $I r f 4^{30}$ a member of the interferon-regulatory factor (IRF) family. ${ }^{31}$ Irf4 expression is induced by antigen receptor or mitogen stimulation ${ }^{32}$ and is restricted to cells of the immune system, ${ }^{33,34}$ playing a critical role in both early ${ }^{35}$ and late B-cell differentiation. ${ }^{30}$ Interestingly, Irf4 upregulation results in spontaneous differentiation of $B$ cells into plasma cells and production of $\operatorname{IgM}$ in the absence of external stimuli. ${ }^{36}$

Several familiarity and genetic studies have indicated that heritable components control the serum levels of $\operatorname{IgE}$, $\operatorname{IgA}$ and $\operatorname{IgG}^{37-39}$ and identified a number of loci 
influencing total serum levels of these antibodies in humans. ${ }^{40-42}$ There is also convincing evidence for parent-offspring effects and genetic heritability in human serum IgM levels ${ }^{37-39}$ as well as evidence for genetic control of natural IgM titers in mammals, ${ }^{43}$ birds $^{44}$ and fish. ${ }^{45}$ However, no linkage evidence for quantitative trait loci influencing serum IgM has been reported and the genetics of the homeostatic regulation of serum IgM remains largely unknown. Here, we characterized a total IgM serum phenotype in mouse inbred strains and performed a genome-wide screen that identified a region on mouse chromosome 13 that contained a locus (loci) controlling IgM serum levels. Searching for the cellular and genetic basis of serum IgM phenotype we correlated the level of serum IgM with the frequency of IgMproducing cells and the expression of the Irf4 gene.

\section{Results}

\section{Serum IgM phenotype}

To investigate the genetic control of serum $\operatorname{IgM}$ we analyzed the IgM concentration in the serum of C57BL/ 6 and $\mathrm{BALB} / \mathrm{c}$ inbred strains. We found that the serum IgM level was lower in C57BL/ 6 than in BALB/c mice, albeit the phenotype showed reduced penetrance (Figure 1). The F1 [C57BL/6 X BALB/c] generation showed an intermediate phenotype and an F2 [C57BL/6 $\mathrm{X} \mathrm{BALB/c]} \mathrm{progeny} \mathrm{of} 136$ mice showed a phenotype spectrum, from low to high values, indicating that alleles controlling the phenotype were segregating in the cross (Figure 1). The serum IgM trait, measured as the logarithm of IgM concentration, was normally distributed in the F2 [C57BL/6 X BALB/c] progeny required for quantitative trait locus (QTL) analysis (data not shown).

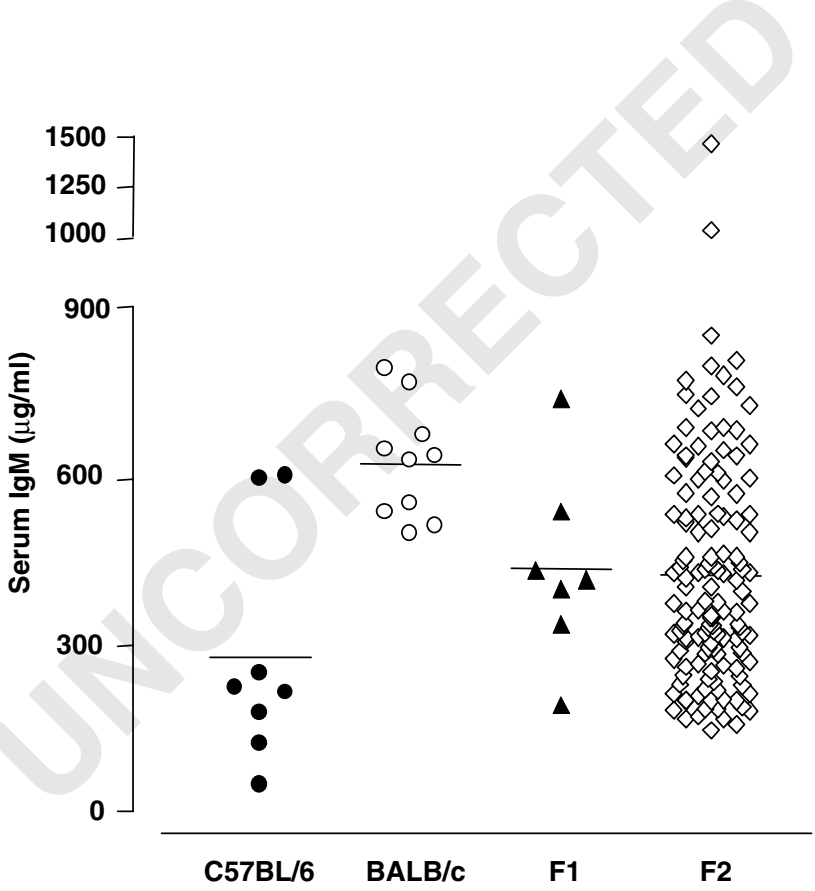

Figure 1 Serum IgM levels in naive mice. IgM serum concentration was measured in eight C57BL/6 (black circles), $10 \mathrm{BALB} / \mathrm{c}$ (white circles), seven F1 [C57BL/6 X BALB/c] (black triangles) and 136 F2 $[\mathrm{C} 57 \mathrm{BL} / 6 \mathrm{X} \mathrm{BALB} / \mathrm{c}]$ (white diamonds) mice by Indirect ELISA. Average concentrations are shown as horizontal bars.

\section{Genetic mapping of serum IgM phenotype}

We performed a QTL analysis for this trait scanning the genome with 100 microsatellite markers in the 136 F2 progeny. We found that a region in proximal mouse chromosome 13 was linked to the serum IgM trait, with a 95\% confidence interval between the markers D13MIT57 and D13MIT179, where the highest associated marker D13Mit266 reached an LOD score of 3.54 corresponding to an empirically estimated genome-wide $P$-value of 0.04 . The chromosome 13 locus was named IgMSC1 (IgMsecreting cells locus 1; Figure 2a) and covered a region encompassing the Irf4 gene. Although no other chromosomal region reached the level of genomic significance, suggestive LOD scores were detected in chromosome 7 at marker D7MIT318 (LOD 2.05) and in chromosome 9 at marker D9MIT53 (LOD 2.02) that could represent
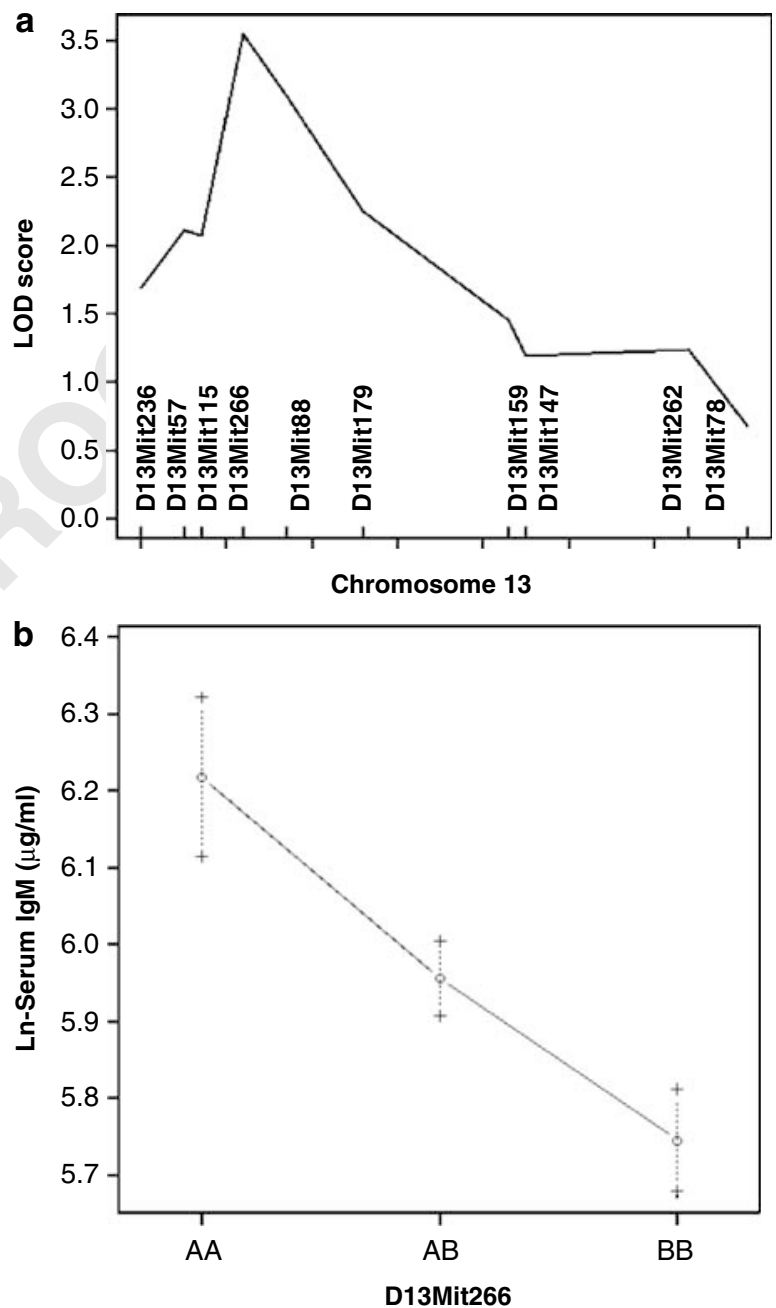

Figure 2 (a) Mapping the IgMSC1 locus. LOD score curve for mouse chromosome 13 represents the likelihood for linkage of the serum IgM trait with the represented markers. Regions of significant linkage show LOD score above 3.0. The $x$ axis ticks represent the relative position of microsatellite markers along this chromosome, from left to right: D13Mit236, $4 \mathrm{cM}$; D13Mit57, $9 \mathrm{cM}$; D13Mit115, 11 cM; D13Mit266, 16 cM; D13Mit88, 21 cM; D13Mit179, $30 \mathrm{cM}$; D13Mit159, $47 \mathrm{cM}$; D13Mit147, $49 \mathrm{cM}$; D13Mit262, $68 \mathrm{cM}$; and D13Mit78, 75 cM. (b) IgM serum trait control by the IgMSC1 locus. The F2 (C57BL/ 6 X BALB/c) mice were classified according to their genotype at D13Mit266 and the mean trait value and the s.e. are represented for each group. 
additional loci controlling the serum IgM phenotype, albeit with a smaller genetic effect as compared with IgMSC1. To evaluate the IgMSC1 genetic effect in the serum IgM phenotype F2 mice were classified according to their genotype at the highest linked marker in the IgMSC1 locus (D13Mit266). This analysis shows that the IgMSC1 locus has an additive mode of action (Figure 2b) and controls a significant fraction of the phenotypic variance $(15.5 \%)$.

\section{IgM-secreting cells and serum IgM}

With the aim of determining the cellular basis of the IgM serum trait we started by counting the total number of $B$ cells, sIgM ${ }^{+} \mathrm{B}$ cells and IgM-secreting cells in the spleen of $\mathrm{C} 57 \mathrm{BL} / 6$ and $\mathrm{BALB} / \mathrm{c}$ adult mice. We found no significant differences in the total number of $B$ cells or in the total number of mature $\operatorname{sIgM}^{+}$B cells (data not shown), suggesting that regulation of B-cell spleen cellularity and B-cell maturation in the spleen is similar in these strains. However, we also found that C57BL/6 have significantly lower number of IgM-secreting cells in the spleen, offering an explanation for the observed lower serum IgM phenotype (Figure 3). Moreover, we purified B-cell populations to show that the number of IgM-secreting cells within splenic B cells was lower in C57BL/6, suggesting that these mice have less efficient plasma cell differentiation as compared with BALB/c mice (Figure 4a). These findings suggested that the cellular basis for the serum IgM trait resides in final steps of the peripheral B-cell maturation and terminal differentiation in the spleen.

It has been described that the B-cell population (B1) localizing in the pleural and peritoneal cavities is an important source of natural IgM in the mouse. ${ }^{46}$ To assess the contribution of peritoneal $B$ cells to the observed phenotype we decided to characterize the population of $\mathrm{B}$ cells and IgM-secreting cells in the peritoneal cavity of C57BL/ 6 and BALB/c mice. We found that C57BL/6 mice have a decreased number of IgM-secreting cells in

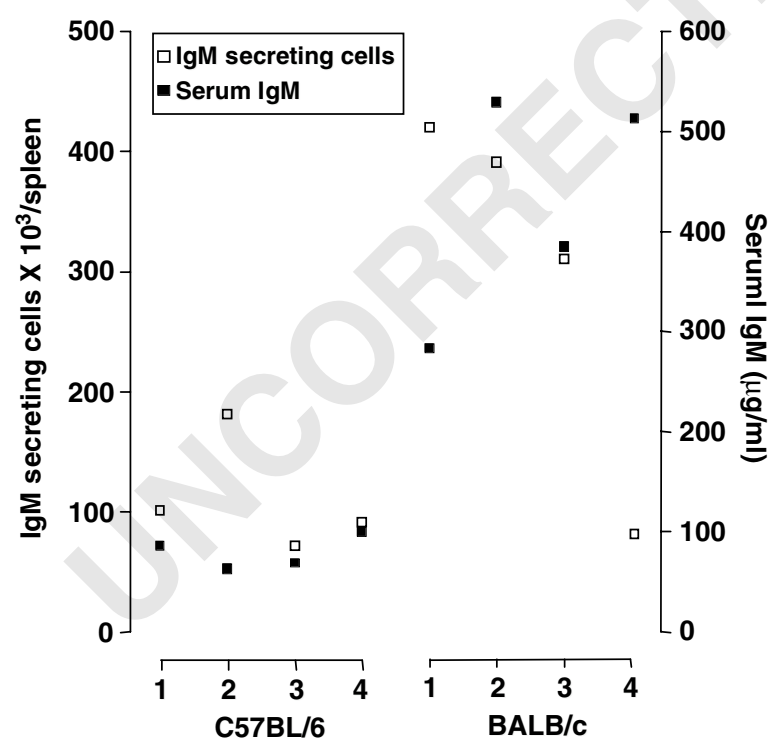

Figure 3 Number of IgM-secreting cells in the spleen correlates with serum IgM concentration. The values represent results that were obtained by ELISA-Spot-Assay and indirect ELISA in individual C57BL/6 and BALB/c mice. the peritoneal cavity when compared with the BALB/c strain (Figure $4 \mathrm{~b}$ ). Thus, the number of IgM-secreting $\mathrm{B}$ cells in the peritoneal cavity may also contribute to the cellular basis of the serum IgM trait in these mouse strains. These data indicate that the reduced number of IgM-secreting cells in the C57BL/6 mice is not specific of the spleen environment and appears to be an intrinsic genetic property of the B-cell compartment.

\section{Irf4 gene expression}

The Irf4 gene is a key player in several stages of B-cell development, namely in controlling plasma cell differentiation $^{30,35}$ and co-localizes with IgMSC1 on chromosome 13. In principle, several genes in the region flanked by D13MIT115 and D13MIT88 that encompass the highest linked marker in the IgMSC1 locus could mediate the observed IgM serum phenotype. Nevertheless, the Irf4 gene is the most plausible functional candidate in this interval as it was earlier related to antibody secretion. ${ }^{30,35}$ To ascertain whether the Irf4 gene could be involved in controlling the serum IgM trait, we quantified Irf4 RNA by real-time PCR in purified B cells from the spleen and the peritoneal cavity. We found that Irf4 expression was significantly reduced in splenic B cells and in peritoneal cavity B cells from the C57BL/6 (Figure 5). These data strongly suggest that Irf4 is a candidate gene to IgMSC1 and contributes to the serum IgM phenotype by controlling the number of IgMsecreting cells.

\section{Discussion}

In this work we used a mouse genome screen approach to search for genetic factors that control the IgM levels in the serum. We identified a major locus on mouse chromosome 13 controlling the IgM serum concentration that we called IgM-secreting cells locus 1 (IgMSC1). Our results support a correlation of this phenotype with the number of IgM-producing cells in the spleen and in the peritoneal cavity, leading us to hypothesize that the IgMSC1 controls IgM serum concentration by regulating the differentiation and/or maintenance of plasma cells both in the spleen and in the peritoneal cavity. It has been described that the serum anti-RBC IgM concentration is linked to the $40-49.5 \mathrm{cM}$ region on chromosome $13^{47}$ and we show that gene(s) controlling natural IgM secretion are also localized in this chromosome. However, the antiRBC locus (40-49.5 cM) and the IgMSC1 locus (9-30 cM) are somewhat apart on chromosome 13 raising the possibility that they would not correspond to the same genetic factor. We noted that the IgG serum concentration in C57BL/6 mice was significantly higher as compared with BALB/c and that IgMSC1 was not controlling levels of serum IgG in the genetic cross we analyzed (data not shown). This indicates that the genetic mechanisms that control IgM and IgG serum steady state levels have distinct and independent components.

The IgMSC1 locus is tightly linked to the Irf4 gene region on mouse chromosome 13 and we showed that the relative expression of this transcription factor is reduced in C57BL/6 B cells isolated from the spleen and from the peritoneal cavity. Thus, we propose the interferon-regulatory factor 4 as a candidate gene to mediate the IgMSC1 phenotypic effect. 

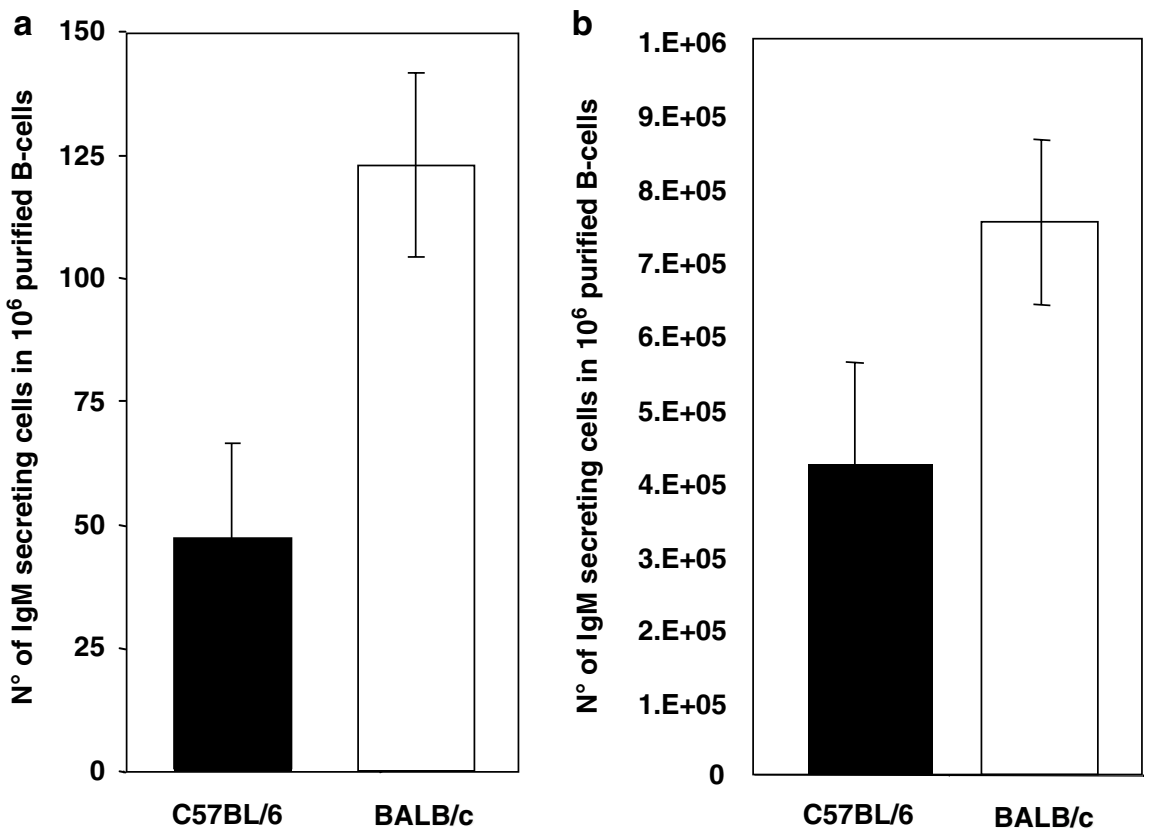

Figure 4 Decreased number of IgM secreting cell counting in purified splenic B cells and purified peritoneal cavity B cells in C57BL/6 mice. (a) Number of IgM-secreting cells in splenocyte B cells pooled from groups of eight mice. The results represent the mean and s.d. of triplicate samples assayed simultaneously. (b) Number of IgM-secreting cells in peritoneal cavity B cells pooled from groups of five mice and representing the mean and s.d. of two separate experiments assayed in triplicates.

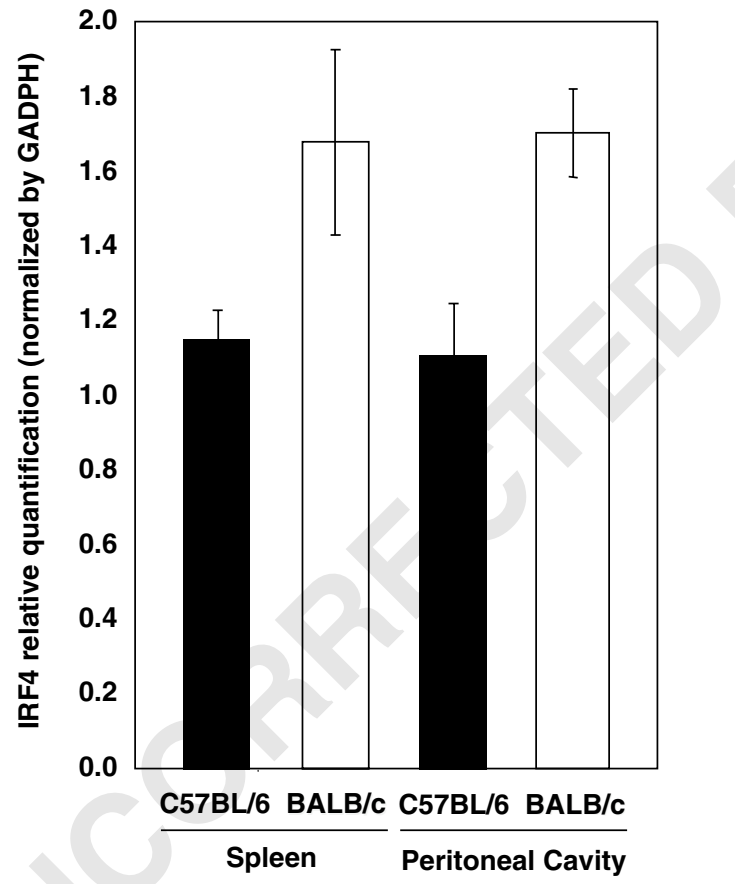

Figure 5 Irf4 gene expression is decreased in purified B cells from the splenic and peritoneal cavity of C57BL/6 mice. RNA of the Irf4 gene was quantified in purified B cells from spleens of five C57BL / 6 (black bars) and five BALB/c (white bars) adult mice or in purified $\mathrm{B}$ cells from pooled peritoneal cavity lavages of five C57BL/ 6 (black column) or five BALB/c (white column) adult mice. The results represent the mean and s.d. of the average of samples assayed simultaneously.

A series of recent studies have demonstrated critical functions for IRF-4 at several stages of B-cell development, where it seems to preferentially limit clonal expansion and promote differentiation processes. ${ }^{32,48}$ Irf4 is a member of the interferon-regulatory factor family of transcription factors characterized by a specific DNA-binding domain and has the ability to either activate or repress the transcription of interferon-inducible genes. ${ }^{18,31}$ Expression of Irf4 is restricted to cells of the immune system, including lymphocytes, dendritic cells and macrophages, in which it has been linked to a variety of functions, such as proliferation, apoptosis and differentiation. ${ }^{33,34,49}$ Irf4 knockout mice have normal early B-cell development but profound reduction in serum immunoglobulin concentrations and show incapability to mount antibody responses because of a latestage blockage in peripheral B-cell maturation that leads to the absence of plasma cells, plasmablasts and classswitched B cells. ${ }^{30,35}$ Recently, the Irf4 gene has been demonstrated to have a biphasic expression pattern: it is expressed in immature B cells in the bone marrow, ${ }^{48}$ absent from proliferating germinal center centroblasts and then re-expressed in a subpopulation of centrocytes in the germinal center and in plasma cells. ${ }^{50}$ Extending these studies, the evidences provided here introduce the notion that natural genetic variation at the Irf4 gene impacts in its expression levels, being a major factor in the quantitative control of terminal B-cell differentiation and, consequently of natural IgM serum concentration.

It is plausible that a differential effect of Irf4 alleles could explain, at least in part, the observed differences in frequency of IgM-secreting cells and IgM serum concentration when we compared the C57BL/ 6 and BALB/c mouse strains. It is reported that the coding region of the Irf4 gene in $\mathrm{C} 57 \mathrm{Bl} / 6$ and $\mathrm{BALB} / \mathrm{C}$ mice shows no sequence differences except for a synonymous point mutation in the exon 6 (NCBI entries with accession numbers AAA75309.1 and AAA75283.1). On the other hand, regulatory elements have been described in the 
human Irf4 gene encompassing the $5 \mathrm{~kb}$ upstream the Irf4 coding region. ${ }^{51}$ However, we have sequenced $4763 \mathrm{bp}$ upstream the translational starting site of the Irf4 gene and did not find sequence differences between C57Bl/ 6 and BALB/C mice. Thus, it is possible that the allelic variation controlling the observed differences in RNA expression lies in yet unidentified Irf4 gene regulatory regions. In fact, the functional conformation of the Irf4 promoter region suggests that its expression is strictly regulated in the chromatin context. ${ }^{51}$ Detailed functional studies of the control region of the mouse Irf4 gene would be needed to enable a systematic analysis of the differential expression of the C57Bl/6 and BALB/c Irf4 alleles.

This work highlighted a region on mouse chromosome 13 that contains genetic factor(s) involved in the circuitry of the serum immunoglobulin homeostasis and led us to hypothesize that allelic variation in the Irf4 gene may control the homeostasis of serum IgM in the mouse at the level of the generation of antibody-producing cells. These findings may motivate human studies on the genetic control of $\operatorname{IgM}$ and natural antibody levels in normal individuals and in the context of Ig deficiencies and inflammatory autoimmune diseases, particularly focused on genes mapping in the region ortholog to IgMSC1, including the Irf4 gene.

\section{Materials and methods}

Mice

The mouse strains used in this study included the C57BL/ 6 and BALB/c as well as mice from the genetic crosses F1 (C57BL/6 X BALB/c) and F2 (C57BL/6 X $\mathrm{BALB} / \mathrm{c})$. All mice were females between 6 and 8 months of age, bred and maintained in conventional housing facilities at the Instituto Gulbenkian de Ciência. F1 (C57BL/6 X BALB/c) mice were used to generate an F2 (C57BL/6 X BALB/c) progeny of 136 animals.

\section{Genotyping}

Genomic DNA was extracted from mouse tails with standard digestion/precipitation methods. The F2 generation was genotyped using 100 microsatellite DNA markers, polymorphic for the parental strains. Markers were chosen according to their chromosomal position as given by the Broad Institute for genome research (USA), to cover uniformly the whole mouse genome at an average density of $20 \mathrm{cM}$. The genotypes for each locus were determined by DNA marker amplification using conventional PCR techniques. Amplification products were analyzed in $4 \%$ agarose gels (Cambrex BioScience, USA) with ethidium bromide (Sigma-Aldrich, USA) and the allele size was determined using the Eagle Eye II video system (Stratagene, USA). Each individual of the F2 progeny was typed for each marker as homozygous for one or the other parental strain or as heterozygous when presenting both the parental strain alleles.

\section{IgM serum concentration}

Standard indirect ELISA was used to quantify total IgM concentrations in mouse sera. Briefly, flat-bottomed 96-well ELISA plates were coated overnight at $4{ }^{\circ} \mathrm{C}$, with goat anti-mouse-IgM-UNLB human adsorbed antibody (Southern Biotech., Birmingham, AL, USA) diluted in coating buffer $\left(0.05 \mathrm{M} \mathrm{Na}_{2} \mathrm{CO}_{3}\right)$. The plates were washed with PBS, blocked with PBS-gelatin $1 \%$ and incubated at $37^{\circ} \mathrm{C}$ for $60 \mathrm{~min}$. After washing, eight serial dilutions of sera to be tested (starting at 1:90 and using 1:3 dilution steps) were incubated for $60 \mathrm{~min}$ at $37^{\circ} \mathrm{C}$ and washed. Bound seric IgM was detected by the peroxidaseconjugated goat anti-mouse IgM-HRP human adsorbed antibody (Southern Biotech.) diluted in PBS-Gelatin $1 \%$-Tween $0.075 \%(1: 4000)$, revealed with the substrate $o$-phenylenediamine (Calbiochem, USA) and $\mathrm{H}_{2} \mathrm{O}_{2}$ and the OD read at $490 \mathrm{~nm}$. The concentrations of $\operatorname{IgM}$ antibody in the samples were calculated against standard curves obtained with purified monoclonal IgM (mouse-IgM UNLB, clone 11E10, Southern Biotech.) tested in the same microtiter plate.

\section{Genetic analysis}

Quantitative trait locus analysis was performed by using the normal model in the R/QTL software. ${ }^{52}$ This program calculates logarithm of odds (LOD scores) over intervals between linked markers, generating likelihood plots of genetic association with the phenotype across the genotyped chromosomal regions. The genome-wide statistical significance of the results was empirically determined by performing permutation tests ${ }^{53}$ and the QTL confidence interval was calculated using the Bayesian method of R/QTL as formulated by Karl Bromam in http://www.rqtl.org/manual/html/bayesint.html.

\section{IgM-secreting cells}

The number of IgM-secreting cells was determined by ELISA-Spot-Assay (ESA). The plates were coated overnight at $4{ }^{\circ} \mathrm{C}$ with goat anti-mouse IgM-human adsorbed (Southern Biotech.), diluted in coating buffer $(0.05 \mathrm{M}$ $\left.\mathrm{Na}_{2} \mathrm{CO}_{3}\right)$ and the plates saturated with PBS containing $1 \%$ gelatin. Serial three-fold dilutions of total splenocytes (starting with $10^{6}$ cells), spleen purified B-cells (starting with $3 \times 10^{6}$ cells) or sorted peritoneal cavity B cells (starting with $7.5 \times 10^{3}$ cells) were performed in RPMI1640 medium supplemented with $10 \%$ heat inactivated fetal calf serum (FCS), $2 \mathrm{~mm}$ L-glutamine, $10 \mathrm{~mm}$ HEPES ( $\mathrm{pH} 7.4), 50 \mathrm{~mm}$ 2-mercaptoethanol, $100 \mathrm{U}$ penicillin and $100 \mathrm{mg} \mathrm{ml}^{-1}$ streptomycin (all from Life Technologies, NY, USA). Cell dilutions were added and the plates were sealed and incubated overnight at $37^{\circ} \mathrm{C}$ in a humidified $5 \% \mathrm{CO}_{2}$ atmosphere. Non-adherent cells were thereafter removed by flicking the plate followed by lysis with $0.1 \%$ Tween 20 in water. After extensive washing with PBS containing $0.05 \%$ Tween 20 the plates were incubated with goat anti-mouse IgM-AP-conjugated antibody (Southern Biotech.), washed again and revealed with BCIP-AMP substrate (2.3 mM of 5-bromo-4-chloro-3indolyl phosphate diluted in 2-amino-2-methyl-1-propanol buffer, Sigma, St Louis, MO, USA). After incubation overnight at $4{ }^{\circ} \mathrm{C}$ and washing three times with distilled water, the traces of IgM-secreting cells were revealed as blue spots and counted.

\section{B-cell purification}

Splenocyte suspensions were prepared by straining of the spleens through a nylon mesh and peritoneal cavity cell suspensions were obtained from peritoneal lavage with $7 \mathrm{ml}$ of PBS supplemented with $2 \%$ FCS. Purified B cells, with an average purity of $98 \%$, were obtained from 
splenocyte and peritoneal cavity cell suspensions through high speed cell sorting (MoFlo, Cytomation Inc., USA), after labeling with FITC-anti-mouse CD19 (clone 1D3, BD Biosciences, CA, USA).

\section{RNA isolation and real-time PCR}

Total RNA from sorted splenic and peritoneal B cells was obtained using an RNeasy Mini Kit (Qiagen), following the manufacturer's protocol for animal cells. RNA was converted to cDNA (Transcriptor First Strand cDNA Irf4 (Mm0051634-m1) expression was quantified using TaqMan Gene Expression Assays from ABI with TaqMan Universal PCR master mix. The gene expression quantification reactions were performed in an ABI Prism $7900 \mathrm{HT}$ system. Relative quantification of Irf4 (Mm0051634-m1) in each real-time PCR was obtained after normalization for GAPDH expression measured in the same PCR and used the $2^{-\Delta \Delta C T}$ analysis method..$^{54}$

\section{Statistical analysis}

Statistically significant differences in serum IgM concentration, B-cell number, IgM-secreting cell number and Irf4-relative expression were estimated by Student's t-test. Differences with $P<0.05$ were considered significant.

\section{Acknowledgements}

We acknowledge Fundacão para a Ciência e Tecnologia for financial support through Grants no. 62964 and SFRH/BD/29212/2006 and thank Jaqueline Garcia for technical assistance in DNA sequencing.

\section{References}

1 Boes M, Prodeus AP, Schmidt T, Carroll MC, Chen J. A critical role of natural immunoglobulin $\mathrm{M}$ in immediate defense against systemic bacterial infection. J Exp Med 1998; 188: 2381-2386.

2 Brown JS, Hussell T, Gilliland SM, Holden DW, Paton JC, Ehrenstein MR et al. The classical pathway is the dominant complement pathway required for innate immunity to Streptococcus pneumoniae infection in mice. Proc Natl Acad Sci USA 2002; 99: 16969-16974.

3 Ochsenbein AF, Fehr T, Lutz C, Suter M, Brombacher F, Hengartner $\mathrm{H}$ et al. Control of early viral and bacterial distribution and disease by natural antibodies. Science 1999; 286: 2156-2159.

4 Boes M, Schmidt T, Linkemann K, Beaudette BC, MarshakRothstein A, Chen J. Accelerated development of IgG autoantibodies and autoimmune disease in the absence of secreted IgM. Proc Natl Acad Sci USA 2000; 97: 1184-1189.

5 Ehrenstein MR, Cook HT, Neuberger MS. Deficiency in serum immunoglobulin (Ig)M predisposes to development of IgG autoantibodies. J Exp Med 2000; 191: 1253-1258.

6 Boes M, Esau C, Fischer MB, Schmidt T, Carroll M, Chen J. Enhanced B-1 cell development, but impaired IgG antibody responses in mice deficient in secreted IgM. J Immunol 1998; 160: 4776-4787.

7 Ehrenstein MR, O'Keefe TL, Davies SL, Neuberger MS. Targeted gene disruption reveals a role for natural secretory $\mathrm{IgM}$ in the maturation of the primary immune response. Proc Natl Acad Sci USA 1998; 95: 10089-10093.

8 Baker N, Ehrenstein MR. Cutting edge: selection of B lymphocyte subsets is regulated by natural IgM. I Immunol 2002; 169: 6686-6690.

9 Brandlein S, Pohle T, Ruoff N, Wozniak E, Muller-Hermelink HK, Vollmers HP. Natural IgM antibodies and immunosurveillance mechanisms against epithelial cancer cells in humans. Cancer Res 2003; 63: 7995-8005.

10 Vollmers HP, Brandlein S. The 'early birds': natural IgM antibodies and immune surveillance. Histol Histopathol 2005; 20: 927-937.

11 Peng Y, Kowalewski R, Kim S, Elkon KB. The role of IgM antibodies in the recognition and clearance of apoptotic cells Mol Immunol 2005; 42: 781-787.

12 Lacroix-Desmazes S, Kaveri SV, Mouthon L, Ayouba A Malanchere E, Coutinho A et al. Self-reactive antibodies (natural autoantibodies) in healthy individuals. J Immunol Methods 1998; 216: 117-137.

13 Bos NA, Meeuwsen CG, Hooijkaas H, Benner R, Wostmann BS, Pleasants JR. Early development of Ig-secreting cells in young of germ-free BALB/c mice fed a chemically defined ultrafiltered diet. Cell Immunol 1987; 105: 235-245.

14 Haury M, Sundblad A, Grandien A, Barreau C, Coutinho A, Nobrega A. The repertoire of serum IgM in normal mice is largely independent of external antigenic contact. Eur J Immunol 1997; 27: 1557-1563.

15 Boes M. Role of natural and immune $\operatorname{IgM}$ antibodies in immune responses. Mol Immunol 2000; 37: 1141-1149.

16 Lydyard PM, Quartey-Papafio R, Broker B, Mackenzie L, Jouquan J, Blaschek MA et al. The antibody repertoire of early human B cells. I. High frequency of autoreactivity and polyreactivity. Scand J Immunol 1990; 31: 33-43.

17 Manson JJ, Mauri C, Ehrenstein MR. Natural serum IgM maintains immunological homeostasis and prevents autoimmunity. Springer Semin Immunopathol 2005; 26: 425-432.

18 Shapiro-Shelef M, Calame K. Regulation of plasma-cell development. Nat Rev Immunol 2005; 5: 230-242.

19 Srivastava B, Quinn III WJ, Hazard K, Erikson J, Allman D. Characterization of marginal zone B cell precursors. J Exp Med 2005; 202: 1225-1234.

20 Chung JB, Silverman M, Monroe JG. Transitional B cells: step by step towards immune competence. Trends Immunol 2003; 24: 343-349.

21 Martin F, Kearney JF. Marginal-zone B cells. Nat Rev Immunol 2002; 2: 323-335.

22 Martin F, Kearney JF. CD21high IgMhigh splenic B cells enriched in the marginal zone: distinct phenotypes and functions. Curr Top Microbiol Immunol 1999; 246: 45-50; discussion 1-2.

23 Oliver AM, Martin F, Gartland GL, Carter RH, Kearney JF Marginal zone B cells exhibit unique activation, proliferative and immunoglobulin secretory responses. Eur J Immunol 1997; 27: $2366-2374$.

24 Holmberg D, Freitas AA, Portnoi D, Jacquemart F, Avrameas $S$, Coutinho A. Antibody repertoires of normal BALB/c mice: B lymphocyte populations defined by state of activation. Immunol Rev 1986; 93: 147-169.

25 Pereira P, Forni L, Larsson EL, Cooper M, Heusser C, Coutinho A. Autonomous activation of $\mathrm{B}$ and $\mathrm{T}$ cells in antigen-free mice. Eur J Immunol 1986; 16: 685-688.

26 Herzenberg LA. B-1 cells: the lineage question revisited. Immunol Rev 2000; 175: 9-22.

27 Hardy RR, Hayakawa K. CD5 B cells, a fetal B cell lineage. Adv Immunol 1994; 55: 297-339.

28 Tumang JR, Frances R, Yeo SG, Rothstein TL. Spontaneously Ig-secreting B-1 cells violate the accepted paradigm for expression of differentiation-associated transcription factors. I Immunol 2005; 174: 3173-3177.

29 Calame KL, Lin KI, Tunyaplin C. Regulatory mechanisms that determine the development and function of plasma cells. Annu Rev Immunol 2003; 21: 205-230. 
30 Klein U, Casola S, Cattoretti G, Shen Q, Lia M, Mo T et al. Transcription factor IRF4 controls plasma cell differentiation and class-switch recombination. Nat Immunol 2006; 7: 773-782.

31 Mamane Y, Heylbroeck C, Genin P, Algarte M, Servant MJ, LePage $C$ et al. Interferon regulatory factors: the next generation. Gene 1999; 237: 1-14.

32 Sciammas R, Shaffer AL, Schatz JH, Zhao H, Staudt LM, Singh $\mathrm{H}$. Graded expression of interferon regulatory factor-4 coordinates isotype switching with plasma cell differentiation. Immunity 2006; 25: 225-236.

33 Pernis AB. The role of IRF-4 in B and T cell activation and differentiation. J Interferon Cytokine Res 2002; 22: 111-120.

34 Marecki S, Fenton MJ. The role of IRF-4 in transcriptional regulation. J Interferon Cytokine Res 2002; 22: 121-133.

35 Mittrucker HW, Matsuyama T, Grossman A, Kundig TM, Potter J, Shahinian A et al. Requirement for the transcription factor LSIRF/IRF4 for mature B and T lymphocyte function. Science 1997; 275: 540-543.

36 Lin L, Gerth AJ, Peng SL. Active inhibition of plasma cell development in resting $\mathrm{B}$ cells by microphthalmia-associated transcription factor. J Exp Med 2004; 200: 115-122.

37 Grundbacher FJ. Heritability estimates and genetic and environmental correlations for the human immunoglobulins G, M, and A. Am J Hum Genet 1974; 26: 1-12.

38 Barbosa CA, Rao DC, Morton NE. Analysis of family resemblance for immunoglobulin M, G and A levels. Hum Hered 1981; 31: 8-14.

39 Borecki IB, McGue M, Gerrard JW, Lebowitz MD, Rao DC Familial resemblance for immunoglobulin levels. Hum Genet 1994; 94: 179-185.

40 Barnes KC, Neely JD, Duffy DL, Freidhoff LR, Breazeale DR, Schou $\mathrm{C}$ et al. Linkage of asthma and total serum IgE concentration to markers on chromosome 12q: evidence from Afro-Caribbean and Caucasian populations. Genomics 1996; 37: 41-50.

41 Mansur AH, Bishop DT, Holgate ST, Markham AF, Morrison JF. Linkage/association study of a locus modulating total serum IgE on chromosome 14q13-24 in families with asthma. Thorax 2004; 59: 876-882.

42 Bleecker ER, Amelung PJ, Levitt RC, Postma DS, Meyers DA. Evidence for linkage of total serum $\operatorname{IgE}$ and bronchial hyperresponsiveness to chromosome 5q: a major regulatory locus important in asthma. Clin Exp Allergy 1995; 25 (Suppl 2): 84-88; discussion 95-6.
43 Gobet R, Cerny A, Ruedi E, Hengartner H, Zinkernagel RM. The role of antibodies in natural and acquired resistance of mice to vesicular stomatitis virus. Exp Cell Biol 1988; 56: 175-180.

44 Parmentier HK, Lammers A, Hoekman JJ, De Vries Reilingh G, Zaanen IT, Savelkoul HF. Different levels of natural antibodies in chickens divergently selected for specific antibody responses. Dev Comp Immunol 2004; 28: 39-49.

45 Kachamakova NM, Irnazarow I, Parmentier HK, Savelkoul HF, Pilarczyk A, Wiegertjes GF. Genetic differences in natural antibody levels in common carp (Cyprinus carpio L.). Fish Shellfish Immunol 2006; 21: 404-413.

46 Herzenberg LA, Stall AM, Lalor PA, Sidman C, Moore WA, Parks DR et al. The Ly-1 B cell lineage. Immunol Rev 1986; 93: 81-102.

47 Lee NJ, Rigby RJ, Gill H, Boyle JJ, Fossati-Jimack L, Morley BJ et al. Multiple loci are linked with anti-red blood cell antibody production in NZB mice-comparison with other phenotypes implies complex modes of action. Clin Exp Immunol 2004; 138: 39-46.

$48 \mathrm{Lu}$ R, Medina KL, Lancki DW, Singh H. IRF-4,8 orchestrate the pre-B-to-B transition in lymphocyte development. Genes Dev 2003; 17: 1703-1708.

49 Fanzo JC, Hu CM, Jang SY, Pernis AB. Regulation of lymphocyte apoptosis by interferon regulatory factor 4 (IRF4). J Exp Med 2003; 197: 303-314.

50 Falini B, Fizzotti M, Pucciarini A, Bigerna B, Marafioti T, Gambacorta $\mathrm{M}$ et al. A monoclonal antibody (MUM1p) detects expression of the MUM1/IRF4 protein in a subset of germinal center B cells, plasma cells, and activated T cells. Blood 2000; 95: 2084-2092.

51 Nishiya N, Yamamoto $\mathrm{K}$, Imaizumi $\mathrm{Y}$, Kohno $\mathrm{T}$, Matsuyama T. Identification of a novel GC-rich binding protein that binds to an indispensable element for constitutive IRF-4 promoter activity in B cells. Mol Immunol 2004; 41: 855-861.

52 Broman KW, Wu H, Sen S, Churchill GA. R/qtl: QTL mapping in experimental crosses. Bioinformatics 2003; 19: 889-890.

53 Lander E, Kruglyak L. Genetic dissection of complex traits: guidelines for interpreting and reporting linkage results. Nat Genet 1995; 11: 241-247.

54 Livak KJ, Schmittgen TD. Analysis of relative gene expression data using real-time quantitative PCR and the 2(-Delta Delta C(T)) Method. Methods 2001; 25: 402-408. 